\title{
Umeclidinium/Vilanterol Versus Tiotropium/ Olodaterol in Maintenance-Naïve Patients with Moderate Symptomatic Chronic Obstructive Pulmonary Disease: A Post Hoc Analysis
}

\author{
Bernardino Alcázar Navarrete · Isabelle Boucot • Ian Naya • \\ Lee Tombs · David A. Lipson · Chris Compton · Ana R. Sousa • \\ Gregory Feldman
}

Received: April 16, 2018 / Published online: June 20, 2018

(C) The Author(s) 2018

\begin{abstract}
Introduction: Appropriate timing for dual bronchodilator therapy initiation in chronic obstructive pulmonary disease (COPD) management is uncertain. Combination therapy is recommended as step-up from monotherapy or first-line treatment in patients with persistent symptoms. In this setting, umeclidinium/
\end{abstract}

Enhanced digital content To view enhanced digital content for this article go to https://doi.org/10.6084/ m9.figshare.6292982.

B. Alcázar Navarrete $(\square)$

Neumología, Hospital de Alta Resolución de Loja, Granada, Spain

e-mail: balcazarnavarrete@gmail.com

I. Boucot · I. Naya · C. Compton

Global Respiratory Franchise, GSK, Brentford,

Middlesex, UK

L. Tombs

Precise Approach Ltd, Contingent Worker on Assignment at GSK, Stockley Park West, Uxbridge, Middlesex, UK

D. A. Lipson

Respiratory Research and Development, GSK, Collegeville, PA, USA

A. R. Sousa

Discovery Medicine, GSK, Stockley Park West,

Uxbridge, Middlesex, UK

G. Feldman

South Carolina Pharmaceutical Research,

Spartanburg, SC, USA vilanterol (UMEC/VI) demonstrated improved lung function and reduced rescue medication use over tiotropium/olodaterol (TIO/OLO). This subgroup analysis explored efficacy differences between these combinations in patients naïve to COPD maintenance therapy before study entry.

Methods: Post hoc analysis of an 8-week, randomized, open-label, assessor-blind, two-period crossover study (204990; NCT02799784) comparing UMEC/VI $62.5 / 25 \mathrm{mcg}$ and TIO/OLO $5 / 5 \mathrm{mcg}$, focused on maintenance-naïve $(\mathrm{MN})$ patients with moderate COPD and persistent symptoms (modified Medical Research Council dyspnea score $\geq 2$ ). Change from baseline (CFB) in trough forced expiratory volume in $1 \mathrm{~s}$ $\left(\mathrm{FEV}_{1}\right)$, percentage of $\mathrm{FEV}_{1}$ responders $(\mathrm{CFB} \geq 100 \mathrm{ml})$, rescue medication use and safety were evaluated.

Results: The MN population comprised $63 \%$ of the intent-to-treat (ITT) population (148/236 patients) and had similar baseline demographics. At week 8, adjusted mean (standard error) improvements in trough $\mathrm{FEV}_{1}$ from baseline were clinically meaningful for both combinations (UMEC/VI: 167 [17] ml; TIO/OLO 110 [18] ml; adjusted mean difference [95\% confidence interval (CI)]: 57 [23-92] ml; $p=0.001$; \%CFB: 11 vs. $8 \%$ ). Proportion of $\mathrm{FEV}_{1}$ responders was greater with UMEC/VI versus TIO/OLO at week 8 (60 vs. $42 \%$; odds ratio [95\% CI] 1.90 [1.12-3.22]; $p=0.018)$. Reduction in rescue medication use was 0.20 (95\% CI $0.07-0.34)$ 
puffs/day greater with UMEC/VI versus TIO/ OLO over weeks 1-8 $(p=0.003)$. Adverse events incidence was similar (UMEC/VI: 24\%; TIO/ OLO: 29\%).

Conclusions: These results highlight that the efficacy difference between UMEC/VI and TIO/ OLO demonstrated in the ITT population is maintained in MN patients. Greater lung function improvements with UMEC/VI versus TIO/ OLO were accompanied by symptom improvements, as reflected in a significantly lower need for supplemental rescue medication.

Funding: GSK.

Trial registration: NCT02799784

Keywords: COPD; LABA; LAMA; Long-acting muscarinic antagonist; Long-acting $\beta_{2}$-agonist; Maintenance-naïve; Olodaterol; Tiotropium; Umeclidinium; Vilanterol

\section{INTRODUCTION}

Inhaled long-acting bronchodilators form the foundation of chronic obstructive pulmonary disease (COPD) therapy, with treatment strategies including long-acting muscarinic antagonist (LAMA) or long-acting $\beta_{2}$-agonist (LABA) monotherapy, or a LAMA/LABA combination, depending on symptom burden and risk of exacerbations [1-4]. The precise timing of when to initiate LAMA/LABA combination therapy is the subject of ongoing scientific debate.

Pharmacological treatment of COPD is usually started late in the course of the disease, often in patients who are already experiencing a significant burden associated with disease symptoms and severe lung function impairment [5]. A majority of patients who receive LAMA or LABA monotherapy continue to experience ongoing moderate-to-severe dyspnea, regardless of the level of lung function impairment [6], and this symptom persistence can be associated with poor health status, as well as a higher risk for moderate and severe exacerbations and augmented disease management costs $[7,8]$. There is now a large body of evidence to show that LAMA/LABA combinations consistently improve lung function, breathlessness and health status with no increased incidence of adverse events (AEs), compared with either LABA or LAMA alone [4, 9-15]. As such, LAMA/LABA combination therapy is recommended as initial therapy in most patients with persistent COPD symptoms [1]. However, LAMA/LABA bronchodilation appear to be similarly beneficial compared with LAMA monotherapy in symptomatic patients who have or have not previously received a COPD maintenance treatment, which questions the rationale for a delayed stepwise approach in managing persistent symptoms $[16,17]$. There is also evidence that early use of LAMA/LABA combinations may improve disease stability compared with LAMA monotherapy by protecting symptomatic patients, including maintenance-naïve $(\mathrm{MN})$ patients, from further disease deterioration [16, 18-20]. Dual therapy could therefore provide the opportunity for maximal bronchodilation, with a view to minimizing daily symptoms, improving quality of life (QoL), and preventing further disease deterioration.

While there is increasing evidence of an efficacy gradient within the LAMA and LAMA/LABA classes with respect to lung function [15, 21-23], the comparative efficacy of different dual bronchodilator combinations used as first-line therapy has not been studied in appropriately symptomatic patients [24]. The LAMA/LABA combinations umeclidinium/vilanterol (UMEC/ VI) $62.5 / 25 \mathrm{mcg}$, delivered via the ELLIPTA dry powder inhaler, and tiotropium/olodaterol (TIO/OLO) $5 / 5 \mathrm{mcg}$, delivered via the Respimat soft mist inhaler, are the only LAMA/LABA combinations approved in the USA, Europe and other parts of the world as once-daily maintenance therapies for COPD [25-28]. The first direct comparison of these once-daily fixed-dose combinations, in an 8-week crossover study in patients with moderate COPD and persistent symptoms of dyspnea, demonstrated the superiority of UMEC/VI over TIO/OLO for the primary endpoint of trough forced expiratory volume in $1 \mathrm{~s}\left(\mathrm{FEV}_{1}\right)$ [21].

With the prospect of early dual bronchodilation for symptomatic patients in mind, further investigation of LAMA/LABA combinations in $\mathrm{MN}$ patients should provide valuable information for clinicians and prescribers to aid 
decision-making. Here, we investigated the efficacy and safety of UMEC/VI and TIO/OLO in a large subgroup of patients from this head-tohead study who were initiated on a COPD maintenance therapy at randomization.

\section{METHODS}

\section{Study Design}

This was a post hoc analysis of an 8-week, multicenter, randomized, open-label, two-period crossover study (NCT02799784; GSK clinical study identifier 204990) conducted in centers across Germany, Spain, UK, and the USA between July 2016 and April 2017 [21]. The objective of the current analysis was to evaluate the efficacy and safety of UMEC/VI versus TIO/ OLO in an unexpectedly large subgroup of patients who were initiated on a COPD maintenance therapy at randomization.

The study was conducted in accordance with the International Conference on Harmonisation of Technical Requirements for Registration of Pharmaceuticals for Human Use Good Clinical Practice guidelines and with principles of the Declaration of Helsinki. The protocol was reviewed and approved by all appropriate institutional review boards (IRBs) or independent ethics committees (Ethik-Komission [Germany], Comite Etico de Investigacion [Spain], Chesapeake IRB [US], and United Kingdom Ethics Committee). Informed consent was obtained from all patients prior to inclusion in the study.

\section{Patients}

Eligibility criteria for enrollment in the study have been previously reported [21]. In brief, patients were $\geq 40$ years of age with a diagnosis of COPD in accordance with the American Thoracic Society/European Respiratory Society (ATS/ERS) definition [29]; current or former smokers with a smoking history of $\geq 10$ packyears; had a pre- and post-bronchodilator $\mathrm{FEV}_{1} /$ forced vital capacity $(\mathrm{FVC})$ ratio $<0.70$ and a post-bronchodilator $\mathrm{FEV}_{1} \leq 70 \%$ and $\geq 50 \%$ of predicted normal values at enrollment (visit 1) [30]; and had a score of $\geq 2$ on the modified Medical Research Council Dyspnea Scale (mMRC) [31].

Patients with any major respiratory disease other than COPD were excluded, as were those who had experienced a moderate/severe exacerbation or lower respiratory tract infection during the run-in period.

\section{Randomization}

Following a 2-week run-in period, eligible patients were randomly assigned to receive one of two treatment sequences: once-daily openlabel UMEC/VI (62.5/25 mcg) administered via the ELLIPTA inhaler (via one inhalation) for 8 weeks followed by once-daily open-label TIO/ OLO (5/5 mcg) administered via the Respimat inhaler (via two puffs of $2.5 / 2.5 \mathrm{mcg}$ ) for 8 weeks, or vice versa. Randomization was an automated process conducted using the RAMOS system. Patients had a 3-week washout period between treatments.

As placebo Respimat inhalers were not available from Boehringer Ingelheim, treatments were administered open label. However, all technicians performing spirometry were blinded to treatment allocation throughout the study.

Maintenance medications for COPD (other than the study medications) were not permitted during any study periods. As-needed use of supplemental albuterol was permitted in the run-in, treatment and washout periods to treat symptoms and provide additional symptomatic relief in the event of breakthrough symptoms on study treatment. Spirometry testing at clinic visits was performed in accordance with ATS/ ERS guidelines and following an appropriate 4-h washout of as-needed albuterol therapy [32].

\section{Endpoints}

The study endpoints have been described previously [21]. The endpoints evaluated in this post hoc analysis were change from baseline 
(CFB) in trough $\mathrm{FEV}_{1}$ ( $\mathrm{ml}$ and ratio to baseline) at weeks 4 and 8 , the proportion of responders at weeks 4 and 8 (defined as $\mathrm{FEV}_{1}$ $\mathrm{CFB} \geq 100 \mathrm{ml}$ ), CFB in trough FVC and inspiratory capacity (IC) at weeks 4 and 8 (derived using spirometry), use of rescue albuterol over weeks 1-8 (puffs per day) captured using an eDiary, change from baseline in COPD Assessment Test (CAT) score and CAT response rate ( $\geq 2$ units decrease in CAT score from baseline) [33] at weeks 4 and 8 , and CFB in daily respiratory symptoms using the Evaluating Respiratory Symptoms-COPD (E-RS $\mathrm{COPD})$ scale (weeks 1-8) [34, 35].

Safety endpoints included the incidence of AEs and serious AEs (SAEs). Moderate and severe exacerbations, defined as worsening of symptoms requiring the use of antibiotics or systemic corticosteroids or a worsening of symptoms requiring hospitalization or an emergency department visit lasting $>24 \mathrm{~h}$, respectively, were also reported descriptively as safety endpoints.

\section{Study Populations}

All randomized patients who received $\geq 1$ dose of study medication were included in the intent-to-treat (ITT) population. The MN population, used for the current post hoc analysis, included all patients who had not received a maintenance treatment (LAMA, LABA alone or in combination \pm ICS) for COPD in the 30 days that records were kept prior to screening, i.e., at least 6 weeks prior to randomization. Permitted treatment included short-acting bronchodilators, anti-infectives (antibiotics, antifungals, antivirals, antiseptics), acute exacerbation treatment, and oxygen therapy. These criteria have been used previously to define $\mathrm{MN}$ populations in studies comparing UMEC/VI with TIO in patients with COPD $[16,17]$.

\section{Statistical Analysis}

Treatment differences are presented as adjusted [least squares (LS)] means or odds ratios (ORs) with 95\% confidence intervals (CI) and $p$ values. Lung function, CAT endpoints, $\mathrm{E}-\mathrm{RS}_{\mathrm{COPD}}$ total score, and rescue medication use were assessed using mixed model repeated measures (MMRM) analysis. Trough $\mathrm{FEV}_{1}$ and CAT responder analyses were performed using a generalized linear mixed model. Covariates have been described previously [21]. Baseline $\mathrm{FEV}_{1}, \mathrm{FVC}$ or IC was the mean of the two assessments taken 30 and 5 min pre-dose on day 1. Baseline CAT score was the score recorded prior to dosing on day 1, baseline E-RS $\mathrm{COPD}_{\mathrm{CO}}$ score and rescue medication use were the means during the week prior to day 1.

\section{RESULTS}

\section{Patient Disposition and Demographics}

The ITT population, described previously [21], comprised 236 patients, of whom 148 (63\%) were included in the $\mathrm{MN}$ population. Baseline characteristics were generally similar between the MN and ITT populations (Table 1); however, the $\mathrm{MN}$ population included a greater proportion of current smokers (MN: 62\%; ITT: 53\%) and a greater proportion of females (MN: 47\%; ITT: $40 \%)$. The MN population also had a higher burden of symptoms, with $44 \%$ of the patients experiencing severe/very severe dyspnea $(\mathrm{mMRC}$ score $\geq 3)$ at baseline compared with $34 \%$ of the ITT population (Table 1 ).

\section{Lung Function}

At week 8, the change from baseline in trough $\mathrm{FEV}_{1}$ was significantly greater in $\mathrm{MN}$ patients during UMEC/VI treatment than TIO/OLO treatment, with LS mean (standard error [SE]) changes of 167 (17) and 110 (18) ml, respectively (adjusted difference $57 \mathrm{ml}$ [95\% CI 23, 92]; $p=0.001$ ) (Table 2 and Fig. 1). A similar magnitude of improvement in trough $\mathrm{FEV}_{1}$ was also observed with UMEC/VI and TIO/OLO at the week 4 visit, with LS mean (SE) changes from baseline of 171 (17) and 117 (17) ml, respectively (adjusted difference $54 \mathrm{ml}$ [95\% CI $23,86] ; p<0.001$ ), highlighting an early plateau in bronchodilation on both treatments (Table 2 and Fig. 1). The percent CFB in trough 
Table 1 Baseline patient demographics and clinical characteristics (overall ITT and MN populations)

\begin{tabular}{lcc}
\hline & Overall ITT $(\boldsymbol{N}=\mathbf{2 3 6})$ & MN subgroup $(\boldsymbol{N}=\mathbf{1 4 8})$ \\
\hline Mean age, years (SD) & $64.4(8.5)$ & $62.9(7.9)$ \\
Male sex, $n$ (\%) & $142(60)$ & $78(53)$ \\
Current smoker at screening, $n$ (\%) & $125(53)$ & $92(62)$ \\
Exacerbation history in the 12 months prior to screening, $n(\%)$ & \\
$\geq 1$ requiring OCS/antibiotics & $33(14)$ & $19(13)$ \\
2 requiring OCS/antibiotics & $4(2)$ & $3(2)$ \\
Requiring hospitalization & $6(3)$ & $3(2)$ \\
Mean post-bronchodilator FEV & \\
ml (SD) & $1734(406)$ & $1722(411)$ \\
$\%$ predicted (SD) & $59.6(5.6)$ & $59.6(5.5)$ \\
Reversible to albuterol ${ }^{2}, n$ (\%) & $86(36)$ & $52(35)$ \\
GOLD 2017 mMRC/exacerbation category $[43], n(\%)$ & $140(95)$ \\
Group B & $224(95)$ & $8(5)$ \\
Group D & $12(5)$ & \\
mMRC score, $n$ (\%) & $156(66)$ & $53(56)$ \\
2 (moderate) & $71(30)$ & $59(40)$ \\
3 (severe) & $9(4)$ & $6(4)$ \\
4 (very severe) & & \\
\hline
\end{tabular}

$F E V_{1}$ forced expiratory volume in $1 \mathrm{~s}, G O L D$ Global Initiative for Chronic Obstructive Lung Disease, ITT intent-to-treat, $m M R C$ modified Medical Research Council, $M N$ maintenance-naïve, $O C S$ oral corticosteroids, $S D$ standard deviation

${ }^{a}$ Reversibility defined as an increase in $\mathrm{FEV}_{1}$ of $\geq 12 \%$ and $\geq 200 \mathrm{ml}$ following administration of bronchodilator

$\mathrm{FEV}_{1}$ (ratio of on-treatment:baseline value) showed an increase in magnitude of response of $11 \%$ on UMEC/VI compared with $8 \%$ on $\mathrm{TIO} /$ OLO at week 8 (between-treatment difference: $3 \%$ [95\% CI 1, 5]; $p=0.004$; Table 2).

A greater proportion of patients achieved a clinically meaningful increase in trough $\mathrm{FEV}_{1}$ ( $\geq 100 \mathrm{ml} \mathrm{CFB}$ ) with UMEC/VI than with TIO/ OLO at week 4 (62 vs. 46\%; OR 1.79 [95\% CI $1.10,2.92] ; p=0.020)$ and at week 8 (60 vs. $42 \%$; OR 1.90 [95\% CI 1.12, 3.22]; $p=0.018$ ).

Within-patient differences between UMEC/ $\mathrm{VI}$ and TIO/OLO in trough $\mathrm{FEV}_{1}$ response at week 8 are presented descriptively in Fig. 2. Overall, $56 \%$ of individuals achieved a clinically meaningful within-patient increase $(\geq 100 \mathrm{ml})$ in trough $\mathrm{FEV}_{1}$ response with UMEC/VI compared with TIO/OLO and $18 \%$ of individuals achieved a clinically meaningful increased response favoring TIO/OLO compared with UMEC/VI, whereas $26 \%$ of patients showed no clinically meaningful benefits in favor of either treatment.

Both FVC and IC improvements were greater with UMEC/VI versus TIO/OLO (adjusted difference: 42 and $71 \mathrm{ml}$ for FVC, 66 and $55 \mathrm{ml}$ for IC, at weeks 4 and 8 , respectively) but at week 4 the treatment difference in favor of UMEC/VI failed to achieve statistical significance for the FVC endpoint (Table 2). 
Table 2 Summary of adjusted on-treatment LS means and change from baseline in lung function in MN patients

\begin{tabular}{|c|c|c|c|}
\hline & $\begin{array}{l}\text { UMEC/VI } \\
(N=147)\end{array}$ & $\begin{array}{l}\text { TIO/OLO } \\
(N=145)\end{array}$ & $\begin{array}{l}\text { Difference }(95 \% \mathrm{CI}) \\
\text { UMEC/VI vs. TIO/OLO; } p \text { value }\end{array}$ \\
\hline \multicolumn{4}{|l|}{ Trough $\mathrm{FEV}_{1}$} \\
\hline Week 4, LS mean (SE), ml & $1753(17)$ & $1699(17)$ & \\
\hline LS mean CFB (SE), ml & $171(17)$ & $117(17)$ & $54(23,86) ; p<0.001$ \\
\hline LS mean ratio to $\mathrm{BL}$ (Logs $\mathrm{SE})$ & $1.11(0.01)$ & $1.08(0.01)$ & $1.03(1.01,1.05) ; p=0.003$ \\
\hline Week 8, LS mean (SE), ml & $1749(17)$ & $1692(18)$ & \\
\hline LS mean CFB (SE), ml & $167(17)$ & $110(18)$ & $57(23,92) ; p=0.001$ \\
\hline $\mathrm{LS}$ mean ratio to $\mathrm{BL}$ (Logs $\mathrm{SE})$ & $1.11(0.01)$ & $1.08(0.01)$ & $1.03(1.01,1.05) ; p=0.004$ \\
\hline \multicolumn{4}{|l|}{ FVC, ml } \\
\hline Week 4, LS mean (SE), ml & $3037(24)$ & $2994(24)$ & \\
\hline LS mean CFB (SE), ml & $199(24)$ & $157(24)$ & $42(-4,89) ; p=0.072$ \\
\hline Week 8, LS mean (SE), ml & $3031(24)$ & $2959(24)$ & \\
\hline LS mean CFB (SE), ml & $193(24)$ & $122(24)$ & $71(27,116) ; p=0.002$ \\
\hline \multicolumn{4}{|l|}{$\mathrm{IC}, \mathrm{ml}$} \\
\hline Week 4, LS mean (SE), ml & $2536(21)$ & $2471(22)$ & \\
\hline LS mean CFB (SE), ml & $161(21)$ & $95(22)$ & $66(19,113) ; p=0.006$ \\
\hline Week 8, LS mean (SE), ml & $2526(21)$ & $2471(21)$ & \\
\hline LS mean CFB (SE), ml & $151(21)$ & $96(21)$ & $55(9,102) ; p=0.02$ \\
\hline
\end{tabular}

All LS means are adjusted for baseline values

$B L$ baseline, $C F B$ change from baseline, $C I$ confidence interval, $F E V_{1}$ forced expiratory volume in $1 \mathrm{~s}, F V C$ forced vital capacity, $I C$ inspiratory capacity, $L S$ least squares, $M N$ maintenance-naïve, $S E$ standard error, TIO/OLO tiotropium/ olodaterol, $U M E C / V I$ umeclidinium/vilanterol

\section{Patient-Reported Outcomes}

The LS mean (SE) reduction from baseline in rescue medication use averaged across all study weeks was greater in patients receiving UMEC/ VI (0.80 [0.10] puffs/day) compared with TIO/ OLO (0.59 [0.10] puffs/day) (difference: 0.20 $[95 \%$ CI $0.07,0.34]$ puffs/day in favor of UMEC/ VI; $p=0.003$ ) (Table 3).

There were no statistically significant differences between UMEC/VI and TIO/OLO in LS mean change from baseline in CAT score or in the proportion of CAT responders $(\geq 2$ units decrease in CAT score from baseline) in the MN population at either week 4 or week 8 (Table 3).

LS mean change from baseline in weekly E-RS ${ }_{\text {COPD }}$ total score ranged from -1.42 to -1.75 for UMEC/VI and from -1.15 to -1.66 for TIO/OLO over weeks 1-8; between-treatment differences were not statistically significant except at week 5, when a statistically significant difference in favor of UMEC/VI was observed (difference -0.58 [95\% CI -1.13 - 0.03]; $p=0.039$ ). 


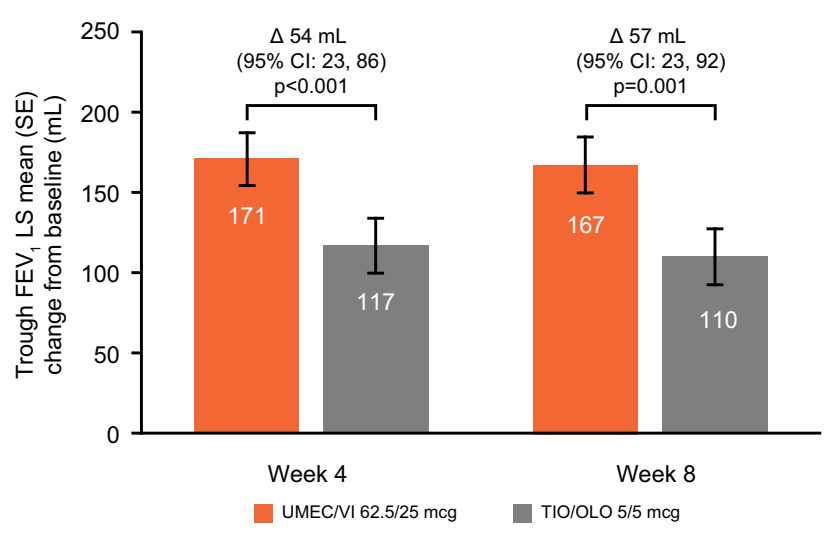

Fig. 1 Improvement in trough $\mathrm{FEV}_{1}$ at weeks 4 and 8 in $\mathrm{MN}$ patients. $C I$ confidence interval, $F E V_{1}$ forced expiratory volume in $1 \mathrm{~s}$, ITT intent-to-treat, $L S$ least squares,
$M N$ maintenance-naïve, $S E$ standard error, TIO/OLO tiotropium/olodaterol; UMEC/VI umeclidinium/ vilanterol

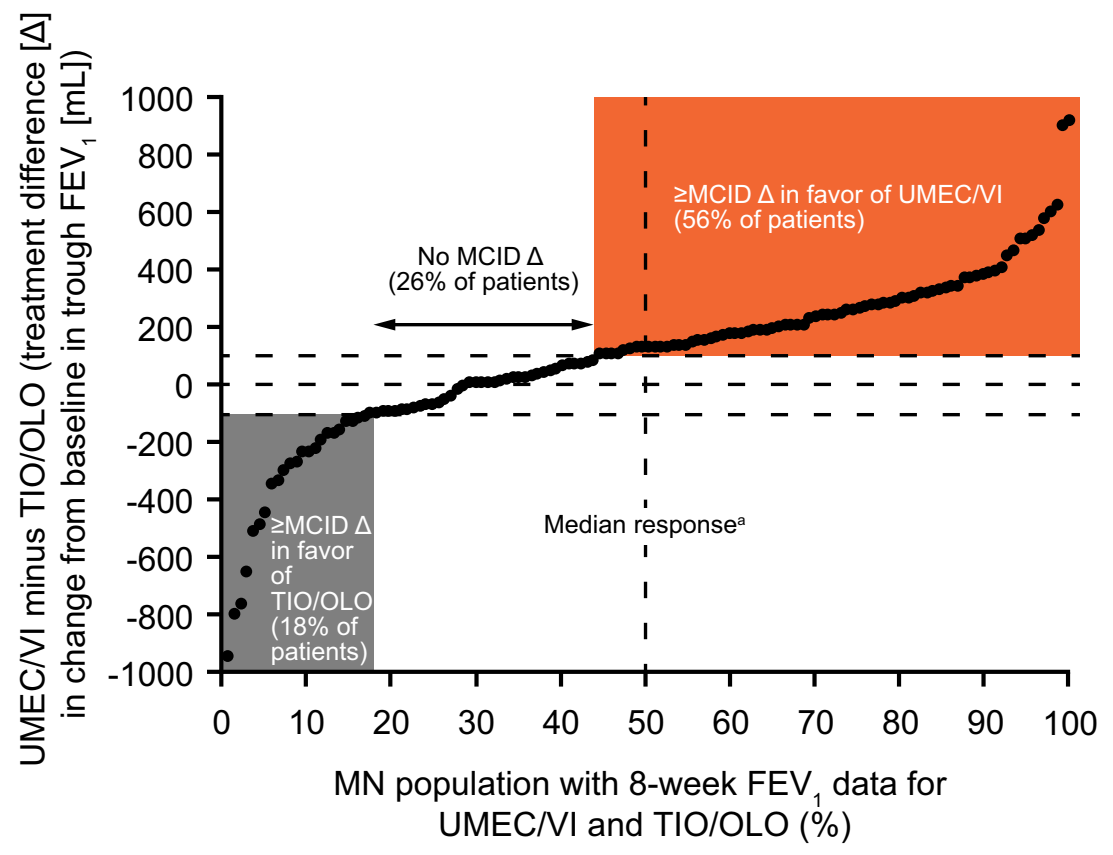

Fig. 2 Distribution of the within-patient treatment differences on trough $\mathrm{FEV}_{1}$ at week 8 for UMEC/VI versus TIO/OLO observed in all individual $\mathrm{MN}$ patients. ${ }^{a}$ Median treatment difference of $130 \mathrm{ml}$ in favor of UMEC/VI. $\Delta$, treatment difference in individual patients (UMEC/VI minus TIO/OLO), $F E V_{1}$ forced expiratory

\section{Safety}

The $\mathrm{AE}$ profiles in the $\mathrm{MN}$ population were similar to those previously reported in the ITT population, with 35 (24\%) patients on UMEC/ VI and 42 (29\%) patients on TIO/OLO experiencing at least one AE. The most frequently volume in $1 \mathrm{~s}$, ITT intent-to-treat, MCID minimal clinically important difference in trough $\mathrm{FEV}_{1}(100 \mathrm{ml})$, $M N$ maintenance-naïve, TIO/OLO tiotropium/olodaterol, $U M E C / V I$ umeclidinium/vilanterol. Values plotted on the graph represent the net baseline-adjusted treatment differences

reported AEs (reported in $\geq 3 \%$ patients on either treatment) for UMEC/VI and TIO/OLO were upper respiratory tract infection (6 [4\%] vs. 6 [4\%] patients), viral upper respiratory tract infection (5 [3\%] vs. 3 [2\%] patients), and sinusitis $(1[<1 \%]$ vs. $4[3 \%]$ patients $)$. 
Table 3 Summary of adjusted on-treatment LS means and change from baseline in patient-reported outcomes in MN patients

\begin{tabular}{lccl}
\hline & $\begin{array}{l}\text { UMEC/VI } \\
(\boldsymbol{N}=\mathbf{1 4 7})\end{array}$ & $\begin{array}{l}\text { TIO/OLO } \\
(\boldsymbol{N}=\mathbf{1 4 5})\end{array}$ & $\begin{array}{l}\text { Difference (95\% CI) } \\
\text { UMEC/VI vs. TIO/OLO; } \boldsymbol{p} \text { value }\end{array}$ \\
\hline $\begin{array}{l}\text { Rescue medication use (puffs/day) } \\
\text { Weeks 1-8, LS mean (SE) }\end{array}$ & $1.59(0.10)$ & $1.79(0.10)$ & \\
LS mean CFB (SE) & $-0.80(0.10)$ & $-0.59(0.10)$ & $-0.20(-0.34,-0.07) ; p=0.003$ \\
CAT score & & & \\
Week 4, LS mean (SE) & $17.44(0.36)$ & $18.04(0.37)$ & $-0.60(-1.35,0.16) ; p=0.119$ \\
LS mean CFB (SE) & $-1.49(0.36)$ & $-0.89(0.37)$ & \\
Week 8, LS mean (SE) & $17.46(0.37)$ & $17.87(0.37)$ & $-0.40(-1.16,0.36) ; p=0.296$ \\
LS mean CFB (SE) & $-1.46(0.37)$ & $-1.06(0.37)$ & OR $(95 \% \mathrm{CI}): 1.27(0.77,2.10) ; p=0.354$ \\
CAT responders ${ }^{\mathrm{b}}$ & & & OR $(95 \% \mathrm{CI}): 1.32(0.80,2.16) ; p=0.278$ \\
Week 4, $n / N(\%)$ & $67 / 145(46)$ & $53 / 140(38)$ & \\
Week 8, $n / N(\%)$ & $68 / 145(47)$ & $54 / 142(38)$ & \\
\hline
\end{tabular}

All LS means are adjusted for baseline values

$C A T$ COPD Assessment Test, $C F B$ change from baseline, $C I$ confidence interval, $L S$ least squares, $M N$ maintenance-naïve, $n$ number of responders, $N$ number of patients with available data, $S E$ standard error, TIO/OLO tiotropium/olodaterol, $U M E C / V I$ umeclidinium/vilanterol

${ }^{a}$ Negative CAT scores indicate clinical improvement

b CAT responder defined as $\geq 2$ unit decrease from baseline in CAT score

On-treatment SAEs occurred in one patient on each treatment, an instance of rib fracture during treatment with UMEC/VI, and an instance of hyperglycemia during treatment with TIO/OLO. No SAEs were considered related to treatment by study investigators. No deaths were reported during the study.

The incidence of COPD exacerbations in MN patients was low and similar between treatments: ten (7\%) patients experienced one exacerbation during UMEC/VI treatment and $12(8 \%)$ during TIO/OLO treatment, while two $(1 \%)$ and one $(<1 \%)$ patient experienced two exacerbations on UMEC/VI and TIO/OLO, respectively.

\section{DISCUSSION}

In this secondary subgroup analysis of the headto-head study of two once-daily LAMA/LABA combinations [21], the focus was exclusively on the $\mathrm{MN}$ subgroup to provide further information around the timing of LAMA/LABA combination therapy initiation. Treatment with UMEC/VI within this subgroup provided significantly greater improvements in trough $\mathrm{FEV}_{1}$, FVC and IC compared with TIO/OLO therapy. The magnitude of the extra treatment benefit observed with UMEC/VI compared with $\mathrm{TIO} / \mathrm{OLO}$ in the MN population, which comprised $63 \%$ of the total ITT population, was broadly consistent with that observed for all lung function outcomes in the ITT population during the original study [21]. In the MN population, UMEC/VI-treated patients had nearly two-fold increased odds of achieving a clinically important lung function benefit on trough $\mathrm{FEV}_{1}$ $(\geq 100 \mathrm{ml} \mathrm{CFB})$ than those who received TIO/ OLO (OR 1.90; $p=0.018$ ); responder rates were $60 \%$ and $42 \%$ at week 8 , respectively. Moreover, in the descriptive analysis of individual variability in patient responses at week 8 , three-fold more $\mathrm{MN}$ patients had trough $\mathrm{FEV}_{1}$ 
increases $\geq 100 \mathrm{ml}$ in favor of UMEC/VI over $\mathrm{TIO} / \mathrm{OLO}$ than vice versa (i.e., 56 vs. $18 \%$ ).

This study was designed to robustly investigate whether or not an efficacy difference existed between the once-daily LAMA/LABA combinations with regards to objectively assessed spirometry. The parent study, and to a greater extent the current post hoc MN subgroup analysis, was not powered to examine improvement in subjective patient-reported outcomes. Nonetheless, as in the parent study, a statistically significantly greater reduction in the need for supplemental rescue bronchodilator medication (a clinical endpoint indicative of treatment effect on symptoms [36]) when patients were treated with UMEC/VI versus TIO/ OLO was also demonstrated in the MN subgroup. Again, the magnitude of this treatment difference was similar to that observed in the ITT population, and comparable to that reported with LAMA monotherapy versus placebo across multiple clinical trials [37, 38]. However, there were no statistically significant betweentreatment differences in the questionnairebased CAT score or E-RS $\mathrm{COPD}_{\text {total score at }}$ week 8. Nevertheless, a numerical difference in the CAT responder analysis was seen at week 8, with $47 \%$ of UMEC/VI-treated patients compared with $38 \%$ of $\mathrm{TIO} / \mathrm{OLO}$-treated patients obtaining clinically relevant improvements in symptoms and health-related QoL, with a similar response rate at week 4 , in line with the primary study. This magnitude of improvement in symptom burden and QoL is consistent with treatment benefit on CAT and other patientreported outcomes seen on escalating therapy from one to two bronchodilators in patients with more advanced COPD [37, 39, 40].

As with the parent study, the benefits observed with UMEC/VI compared with TIO/ OLO were not accompanied by any increased potential for AEs and SAEs, with safety profiles comparable between both bronchodilators in the $\mathrm{MN}$ population. Likewise, a low proportion of patients in the $\mathrm{MN}$ population experienced exacerbations on both treatments. These findings confirm the favorable safety profile of the LAMA/LABA class versus mono bronchodilator therapy documented in long-term efficacy studies [13].
With a growing body of evidence demonstrating the benefits of dual bronchodilation over monotherapy in a number of clinical settings $[4,9-12,41]$, focus is now turning to the relative benefits of different bronchodilator combinations [14]. Indirect evidence from network meta-analyses indicate an efficacy gradient within the LAMA/LABA class with respect to lung function $[14,15,23]$, and this study, the first head-to-head study of UMEC/VI and TIO/ OLO, confirmed the results of the indirect comparisons in both an all-comer and $\mathrm{MN}$ population [21]. The study enrolled patients with a mMRC dyspnea score $\geq 2$ [21], indicating they had a significant symptom burden and associated level of impairment in activity at enrollment. Results from this analysis show that initiation of dual bronchodilator therapy in a MN subgroup of this symptomatic population leads to significant lung function benefits of a similar magnitude to those obtained in the ITT population [21]. Importantly, the treatment difference between the LAMA/LABA combinations observed in this study was greater in magnitude than that reported with TIO/OLO versus TIO alone in a similar $\mathrm{MN}$ population in the replicate OTEMTO studies [17]. Using dual therapy as a first-line maintenance therapy has been shown to provide the opportunity for improved bronchodilation and therefore potential for optimal symptom management and greater protection against further disease deterioration [16-18]. The greater lung function improvements with UMEC/VI over TIO/OLO in this $\mathrm{MN}$ population suggest that there is no ceiling to bronchodilation potential in patients with moderate COPD. Furthermore, demonstration of a statistically significant treatment difference on supplemental rescue medication use, a clinical endpoint reflecting an effect on symptoms [36], shows that the potential for better symptom control with improved bronchodilation in $\mathrm{MN}$ patients is also a realistic goal. Currently, data on the impact of initiating maintenance therapy with dual bronchodilators in $\mathrm{MN}$ patients are sparse and are largely obtained using post hoc analysis of prospectively collected data $[16,17,24]$. These analyses consistently indicate no diminished patient benefit or safety concern when opting to use 
dual therapy as a first-line treatment option. Nevertheless, prospective studies are still needed in this area. Our study in MN patients has similar limitations, however, as the study findings were fully in line with the a priori study results in the ITT population [21], these data do provide further supportive evidence for the efficacy gradient between LAMA/LABA combinations. Moreover, as lung function and symptom improvements were observed with both dual regimens in this $\mathrm{MN}$ population, these data suggest that early approaches aimed at maximizing lung function are appropriate in symptomatic patients and are supportive of the use of dual bronchodilation as a first-line treatment.

The current analysis is the first direct comparison of dual bronchodilator regimens in a MN population. This population, although small in size, is arguably ideal to assess the efficacy differences between bronchodilators in the same treatment class. For instance, assessments of efficacy are not likely to be influenced by prior medication use in a MN population, as can occur with patients switching between existing maintenance therapies, having treatment withdrawn or being re-randomized to a treatment they have had previously. In our study, the MN population had not received a COPD maintenance therapy for at least 6 weeks preceding randomization. Although it cannot be confirmed whether or not patients had received maintenance therapy at an earlier time point, this period should be sufficient to ensure our definition of a $\mathrm{MN}$ population is representative. Moreover, the mean predicted baseline $\mathrm{FEV}_{1}$ of $60 \%$ suggests that this is likely to be representative of a general population initiating a maintenance therapy. The population was also slightly younger than the overall ITT population and had a higher proportion of current smokers, trends that were also seen in the OTEMTO analysis [17].

As with the original study, the design features must also be noted when considering the limitations of this analysis. These include the open-label administration of treatments and the potentially short 8-week study duration. In order to mitigate any potential for bias on the primary outcome, the technicians performing spirometry were blinded to treatment allocation within each study period. Furthermore, the randomized, crossover nature of the study, and the objective measurements of primary efficacy $\left(\mathrm{FEV}_{1}\right)$ and safety variables were designed to minimize any bias [42]. Moreover, the 8-week study duration was deemed to be sufficient to allow robust assessments of bronchodilator response given that a plateau in response was detected after 4 weeks in the ITT and MN population with both treatments [21]. However, the study duration may have been too short to fully assess differences in longer-term outcomes such as the rate of exacerbations and changes in QoL over time. Despite these limitations, the data demonstrate that UMEC/VI improves lung function and at least one symptom measure versus TIO/OLO in MN patients. Finally, the addition of a third monotherapy arm, which could be considered as standard of care in a MN population, could have aided the interpretation of results and would have been a valuable addition to this analysis.

\section{CONCLUSIONS}

This post hoc analysis in a subgroup of patients naïve to COPD maintenance therapy was consistent with the primary a priori parent analysis, highlighting that an efficacy gradient exists within the LAMA/LABA class favoring oncedaily UMEC/VI over TIO/OLO. Further longterm, prospective studies into the effect of initiation of dual bronchodilator versus monotherapy as a first-line maintenance therapy are now needed to build on these shortterm efficacy and safety findings.

\section{ACKNOWLEDGMENTS}

Funding. This study, post hoc analysis and the article processing charges were funded by GSK (Study Number: 204990). The funders of the study had a role in study design, data analysis, data interpretation, and writing of the report. 
Medical Writing and/or Editorial Assistance. Editorial support (in the form of writing assistance during development of the initial draft, assembling tables and figures, collating authors comments, grammatical editing, and referencing) was provided by Rachel Edwards and Chrystelle Rasamison at Fishawack Indicia Ltd, UK, and was funded by GSK.

Authorship. All named authors meet the International Committee of Medical Journal Editors (ICMJE) criteria for authorship for this manuscript, take responsibility for the integrity of the work as a whole, contributed to the writing and reviewing of the manuscript, and have given final approval of the version to be published.

Authors' Contributions. ARS, DAL, IN, and $\mathrm{CC}$ were involved in the conception and design of the study and data analysis and interpretation. LT was involved in the conception and design of the study, acquisition of data, and data analysis and interpretation. IB was involved in data analysis and interpretation. BAN and GF were involved in the acquisition of data and data analysis and interpretation.

Disclosures. Ana R. Sousa is an employee of GSK and hold stocks and shares in GSK. Chris Compton is an employee of GSK and hold stocks and shares in GSK. David A. Lipson is an employee of GSK and hold stocks and shares in GSK. Isabelle Boucot is an employee of GSK and hold stocks and shares in GSK. Ian Naya is an employee of GSK and hold stocks and shares in GSK. Lee Tombs is a contingent worker on assignment at GSK. Bernardino Alcázar Navarrete reports personal fees and non-financial support from GSK, grants, personal fees and non-financial support from Novartis AG, personal fees and non-financial support from Boehringer Ingelheim, personal fees and non-financial support from Chiesi, grants, personal fees and non-financial support from Laboratorios Menarini, personal fees from Gebro, personal fees from AstraZeneca, outside the submitted work. In addition, Bernardino Alcázar Navarrete has a patent (P201730724) pending. Gregory Feldman has nothing to disclose.

Ellipta is owned by or licensed to the GlaxoSmithKline group of companies. Respimat is a registered trademark of Boehringer Ingelheim.

Compliance with Ethics Guidelines. The 204990 study was conducted in accordance with International Conference on Harmonisation of Technical Requirements for Registration of Pharmaceuticals for Human Use-Good Clinical Practice guidelines and the principles of the Declaration of Helsinki. The protocol was reviewed and approved by all appropriate institutional review boards (IRB) or independent ethics committees (Ethik-Komission [Germany], Comite Etico de Investigacion [Spain], Chesapeake IRB [US] and United Kingdom Ethics Committee). Informed consent was obtained from all patients prior to inclusion in the study.

Data Availability. The datasets used and/or analyzed during the current study are available from the corresponding author on reasonable request.

Open Access. This article is distributed under the terms of the Creative Commons Attribution-NonCommercial 4.0 International License (http://creativecommons.org/licenses/ by-nc/4.0/), which permits any noncommercial use, distribution, and reproduction in any medium, provided you give appropriate credit to the original author(s) and the source, provide a link to the Creative Commons license, and indicate if changes were made.

\section{REFERENCES}

1. Global Initiative for Chronic Obstructive Lung Disease. Global strategy for the diagnosis, management and prevention of chronic obstructive pulmonary disease updated 2018. http://goldcopd. org/. Accessed 21 Feb 2018.

2. Cazzola M, Page CP, Calzetta L, Matera MG. Pharmacology and therapeutics of bronchodilators. Pharmacol Rev. 2012;64:450-504. 
3. Tashkin DP, Cooper CB. The role of long-acting bronchodilators in the management of stable COPD. Chest. 2004;125:249-59.

4. Tashkin DP, Ferguson GT. Combination bronchodilator therapy in the management of chronic obstructive pulmonary disease. Respir Res. 2013;14:49.

5. Decramer M, Cooper CB. Treatment of COPD: the sooner the better? Thorax. 2010;65:837-41.

6. Dransfield MT, Bailey W, Crater G, Emmett A, O'Dell DM, Yawn B. Disease severity and symptoms among patients receiving monotherapy for COPD. Prim Care Respir J. 2011;20:46-53.

7. Punekar YS, Mullerova H, Small M, et al. Prevalence and burden of dyspnoea among patients with chronic obstructive pulmonary disease in five European countries. Pulm Ther. 2016;2:59-72.

8. Agusti A, Edwards LD, Celli B, et al. Characteristics, stability and outcomes of the 2011 GOLD COPD groups in the ECLIPSE cohort. Eur Respir J. 2013;42:636-46.

9. Bateman ED, Ferguson GT, Barnes N, et al. Dual bronchodilation with QVA149 versus single bronchodilator therapy: the SHINE study. Eur Respir J. 2013;42:1484-94.

10. Decramer M, Anzueto A, Kerwin E, et al. Efficacy and safety of umeclidinium plus vilanterol versus tiotropium, vilanterol, or umeclidinium monotherapies over 24 weeks in patients with chronic obstructive pulmonary disease: results from two multicentre, blinded, randomised controlled trials. Lancet Respir Med. 2014;2:472-86.

11. Tashkin DP, Pearle J, Iezzoni D, Varghese ST. Formoterol and tiotropium compared with tiotropium alone for treatment of COPD. COPD. 2009;6:17-25.

12. van der Molen T, Cazzola M. Beyond lung function in COPD management: effectiveness of LABA/ LAMA combination therapy on patient-centred outcomes. Prim Care Respir J. 2012;21:101-8.

13. Oba Y, Sarva ST, Dias S. Efficacy and safety of longacting beta-agonist/long-acting muscarinic antagonist combinations in COPD: a network meta-analysis. Thorax. 2016;71:15-25.

14. Calzetta L, Rogliani P, Matera MG, Cazzola M. A systematic review with meta-analysis of dual bronchodilation with LAMA/LABA for the treatment of stable COPD. Chest. 2016;149:1181-96.

15. Sion KYJ, Huisman EL, Punekar YS, Naya I, Ismaila AS. A network meta-analysis of long-acting muscarinic antagonist (LAMA) and long-acting $\beta_{2^{-}}$ agonist (LABA) combinations in COPD. Pulm Ther. 2017;3:297-316.

16. Maleki-Yazdi MR, Singh D, Anzueto A, Tombs L, Fahy WA, Naya I. Assessing short-term deterioration in maintenance-naive patients with COPD receiving umeclidinium/vilanterol and tiotropium: a pooled analysis of three randomized trials. Adv Ther. 2017;33:2188-99.

17. Singh D, Gaga M, Schmidt $O$, et al. Effects of tiotropium + olodaterol versus tiotropium or placebo by COPD disease severity and previous treatment history in the OTEMTO(R) studies. Respir Res. 2016;17:73.

18. Anzueto AR, Vogelmeier CF, Kostikas K, et al. The effect of indacaterol/glycopyrronium versus tiotropium or salmeterol/fluticasone on the prevention of clinically important deterioration in COPD. Int J Chron Obstruct Pulmon Dis. 2017;12:1325-37.

19. Singh D, Maleki-Yazdi MR, Tombs L, Iqbal A, Fahy WA, Naya I. Prevention of clinically important deteriorations in COPD with umeclidinium/vilanterol. Int $\mathrm{J}$ Chron Obstruct Pulmon Dis. 2016;11:1413-24.

20. Singh D, D’Urzo AD, Chuecos F, Munoz A, Garcia Gil E. Reduction in clinically important deterioration in chronic obstructive pulmonary disease with aclidinium/formoterol. Respir Res. 2017;18:106.

21. Feldman GJ, Sousa AR, Lipson DA, et al. Comparative efficacy of once-daily umeclidinium/vilanterol and tiotropium/olodaterol therapy in symptomatic chronic obstructive pulmonary disease: a randomized study. Adv Ther. 2017;34:2518-33.

22. Feldman G, Maltais F, Khindri S, et al. A randomized, blinded study to evaluate the efficacy and safety of umeclidinium $62.5 \mathrm{mcg}$ compared with tiotropium $18 \mathrm{mcg}$ in patients with COPD. Int J Chron Obstruct Pulmon Dis. 2016;11:719-30.

23. Schlueter M, Gonzalez-Rojas N, Baldwin M, Groenke L, Voss F, Reason T. Comparative efficacy of fixed-dose combinations of long-acting muscarinic antagonists and long-acting beta2-agonists: a systematic review and network meta-analysis. Ther Adv Respir Dis. 2016;10:89-104.

24. Welte T, Vogelmeier C, Papi A. COPD: early diagnosis and treatment to slow disease progression. Int J Clin Pract. 2015;69:336-49.

25. STIOLTO ${ }^{\mathrm{TM}}$ RESPIMAT $^{\circledR}$ Highlights of Prescribing Information. https://www.accessdata.fda.gov/ drugsatfda_docs/label/2015/206756s001lbl.pdf. Accessed 21 Feb 2018. 
26. ANORO $^{\mathrm{TM}}$ ELLIPTA $^{\circledR}$ Highlights of prescribing information. https:/www.accessdata.fda.gov/drug satfda_docs/label/2013/203975s000lbl.pdf. Accessed 21 Feb 2018.

27. $\mathrm{ANORO}^{\mathrm{TM}}$ Summary of Product Characteristics. http://www.ema.europa.eu/docs/en_GB/document _library/EPAR_-_Product_Information/human/002 751/WC500168424.pdf. Accessed 21 Feb 2018.

28. New advance in COPD maintenance treatment, Spiolto $^{\circledR}$ Respimat $^{\circledR}$, approved in first European countries. https://www.boehringer-ingelheim.com/ press-release/new-advance-copd-maintenance-trea tment-spiolto-respimat-approved-first-european. Accessed 21 Feb 2018.

29. Celli BR, MacNee W, Force AET. Standards for the diagnosis and treatment of patients with COPD: a summary of the ATS/ERS position paper. Eur Respir J. 2004;23:932-46.

30. Hankinson JL, Odencrantz JR, Fedan KB. Spirometric reference values from a sample of the general U.S. population. Am J Respir Crit Care Med. 1999;159:179-87.

31. Mahler DA, Wells CK. Evaluation of clinical methods for rating dyspnea. Chest. 1988;93:580-6.

32. Miller MR, Hankinson J, Brusasco V, et al. Standardisation of spirometry. Eur Respir J. 2005;26:319-38.

33. Jones PW, Harding G, Berry P, Wiklund I, Chen WH, Kline Leidy N. Development and first validation of the COPD Assessment Test. Eur Respir J. 2009;34:648-54.

34. Leidy NK, Murray LT, Monz BU, et al. Measuring respiratory symptoms of COPD: performance of the EXACT- respiratory symptoms tool (E-RS) in three clinical trials. Respir Res. 2014;15:124.

35. Leidy NK, Sexton CC, Jones PW, et al. Measuring respiratory symptoms in clinical trials of COPD: reliability and validity of a daily diary. Thorax. 2014;69:443-9.
36. European Medicines Agency. Guideline on clinical investigation of medicinal products in the treatment of chronic obstructive pulmonary disease (COPD) 2012. http://www.ema.europa.eu/docs/en GB/document_library/Scientific_guideline/2012/ 08/WC500130880.pdf. 21 June 2012.

37. Siler TM, Kerwin E, Tombs L, Fahy WA, Naya I. Triple therapy of umeclidinium + inhaled corticosteroids/long-acting beta2 agonists for patients with COPD: pooled results of randomized placebocontrolled trials. Pulm Ther. 2016;2:43-58.

38. Donohue JF, Jones PW, Bartels C, et al. Correlations between FEV1 and patient-reported outcomes: a pooled analysis of 23 clinical trials in patients with chronic obstructive pulmonary disease. Pulm Pharmacol Ther. 2018;49:11-9.

39. Lipson DA, Barnacle H, Birk R, et al. FULFIL trial: once-daily triple therapy for patients with chronic obstructive pulmonary disease. Am J Respir Crit Care Med. 2017;196:438-46.

40. Buhl R, Maltais F, Abrahams R, et al. Tiotropium and olodaterol fixed-dose combination versus mono-components in COPD (GOLD 2-4). Eur Respir J. 2015;45:969-79.

41. Ferguson GT, Karpel J, Bennett N, et al. Effect of tiotropium and olodaterol on symptoms and patient-reported outcomes in patients with COPD: results from four randomised, double-blind studies. NPJ Prim Care Respir Med. 2017;27:7.

42. Beeh KM, Beier J, Donohue JF. Clinical trial design in chronic obstructive pulmonary disease: current perspectives and considerations with regard to blinding of tiotropium. Respir Res. 2012;13:52.

43. Global Initiative for Chronic Obstructive Lung Disease. Global strategy for the diagnosis, management and prevention of chronic obstructive pulmonary disease updated 2017. http://goldcopd.org/. Accessed 21 Feb 2018. 